\title{
THE IMPACT OF THE USE OF AMALGAM IN DENTAL TREATMENT ON THE PREVALENCE OF RESTLESS LEGS SYNDROME IN OLDER PEOPLE
}

\author{
Magdalena Szklarek, Tomasz Kostka \\ Medical University of Lodz, Łódź, Poland \\ Department of Geriatrics, Healthy Ageing Research Centre
}

\begin{abstract}
Background: The link between restless legs syndrome (RLS) and the number of amalgam fillings in older people was investigated. Restless legs syndrome decreases the quality of life and impairs normal functioning. Mercury (in amalgam) may be toxic to nerve cells and may account for the incidence of RLS. Material and Methods: The relationship between RLS and the presence of amalgam in the teeth of 104 people aged 60-97 years old was determined. By using 4 questions, together with the diagnostic criteria from the internationally used questionnaire produced by the International Restless Legs Syndrome Study Group (IRLSSG), authors assessed the extent of the symptoms and occurrence of RLS. Careful medical history and medical examination were used for ascertaining each subject's type of restorative materials (i.e., amalgam or other metal) and the number of such fillings. Results: Subjects who answered "yes" (indicating presence of RLS) to the 4 subsequent questions had a significantly higher number of amalgam dental fillings as compared to the subjects without RLS symptoms. Presence of other metal dental restorative materials and the number of amalgam dental fillings reported in the past had no significant influence on RLS symptomatology. Conclusions: Authors conclude that while examining the correlates of the appearance of restless legs syndrome the use of amalgam in the dentition should be taken into account. Med Pr. 2019;70(1):9-16
\end{abstract}

Key words: elderly, amalgam, restless legs syndrome, questionnaires, lesions to brain cells, exposure to mercury

Corresponding author: Magdalena Szklarek, Medical University of Lodz, Department of Geriatrics,

Healthy Ageing Research Centre, Pieniny 30, 92-003 Łódź, Poland, e-mail: magdalena.szklarek@gmail.com

Received: January 19, 2018, accepted: July 19, 2018

\section{INTRODUCTION}

Restless legs syndrome/Willis-Ekbom disease (RLS/WED or RLS) is a real problem to patients and the correct diagnosis often takes years. Its symptoms are diverse and distressing. In 1944 Ekbom gave the first clinical description, although Willis discovered it in 1672 . Willis's quote dating back to 17th century is as follows: "whilst they would indulge in sleep, in their beds, immediately follow leapings of the tendons, in their arms and legs, with cramps, and such unquietness and flying about of their members, that the sick can no more sleep than those on the rack" [1].

Restless legs syndrome is a debilitating chronic condition affecting all age groups, particularly the elderly, causing insomnia and significantly decreasing their quality of life (QoL) [2]. In the general population, the prevalence of RLS has been estimated at up to $25 \%$, increasing in the older population. Women are approx- imately twice as likely to suffer as men [3]. Overall, patients with RLS have poorer health, more frequent depression and increased risk of death [4].

A diagnosis of RLS is based on a clinical history. Leg restlessness during the night is a leading complaint. The isolated involvement of other body parts, without leg involvement, is also possible, with large proportion of patients having arm paraesthesia and restlessness. In 2003 specific diagnostic criteria were developed by Allen et al. for the cognitively impaired elderly and updated in August 2014, so that an accurate diagnosis of RLS could be determined, and its symptoms would not be confused with those of other conditions [5].

The idiopathic form of RLS is known as primary RLS. If the RLS is ascribed to an existing medical condition (e.g., renal disease), it is called secondary RLS. Among various illnesses, the toxic influences of various metals, especially that of mercury $(\mathrm{Hg})$, have been considered in the literature [6]. Mercury is known to damage the

Funding: this work was supported by the Medical University of Lodz (grant No. 503/6-077-01/503-61-002-17 entitled "Determinants of functional capacity in the elderly," grant manager: prof. Tomasz Kostka). 
cardiovascular system, kidneys and the central nervous system. Xu et al. demonstrated that mercury had a toxic effect on the neurons in the brain [7]. Mercury has been implicated in causing deposition of immune-complexes [8] thus leading to glomerular disease.

Our bodies are exposed to mercury throughout our lifetime from a variety of sources. Mercury is present in amalgam filling, widely used by dentists, generally in the past. Amalgam fillings contain $50 \%$ of $\mathrm{Hg}$, together with other metals $(\mathrm{Cu}, \mathrm{Sn}, \mathrm{Ag}$ and $\mathrm{Zn})$. The mercury vapor is released during daily routine activities, e.g., chewing. Bjorkman's work showed that dietary mercury and mercury coming from dental amalgam restorations may be concentrated in the brain [9].

Interestingly, in the existing literature authors have not found studies assessing symptoms of RLS as a potential manifestation of $\mathrm{Hg}$ toxicity in relationship to amalgam fillings use. Therefore, authors have undertaken the study into the prevalence of RLS and its connection to the presence of amalgam fillings.

\section{MATERIAL AND METHODS}

Research was carried out in a Polish Housing Society in Penrhos, North West Wales, founded in 1949, providing accommodation and support to Polish ex-service men and women who remained in the UK following World War II. These people live independently within the society's houses or flats and have access to communal dining and social areas plus a church. In order to eliminate potential confounding factors subjects with significant health problems, that could influence the measurements to be performed in the study, were excluded. The exclusion criteria were being bed- or wheelchair-bound and poor mental health. The criteria for inclusion in the study, were older age, satisfactory verbal communication and ability to perform functional tests. Thus, 24 subjects out of 128 , who were either temporary or permanent residents of this housing association's nursing home were excluded. The study finally comprised 104 elderly cognitively normal, relatively healthy volunteers (70 women and 34 men) between 60 and 97 years of age. Participants were free from terminal illness, major disabilities or severe dementia. The study was approved by an ethics committee of the Medical University of Lodz and written and informed consent was obtained from all subjects.

All subjects were interviewed to obtain a full medical history including regular medication taken. With the patient's consent, the nursing staff filled in any gaps in their disease history. Information about alcohol intake and smoking was gathered. The number of amalgam fillings, dental restorative materials historical and/ or present were noted from medical documentation and dental examination. The diagnosis of RLS is purely clinical and is based on the information obtained during an interview with the patient. Authors applied the diagnostic criteria of the International Restless Legs Syndrome Study Group (IRLSSG) in the form of 4 questions of the internationally used questionnaire in order to determine the appearance of the problem of RLS. The International Restless Legs Syndrome Study Group Severity Rating Scale was used in order to identify the severity of the disease [10].

Multidimensional questionnaires were used for determining mental status and physical efficiency. Mental functions were assessed using Mini-Mental State Examination questionnaire (MMSE) [11] and 15-item Yesavage Geriatric Depression Scale (GDS) [12].

The physical activity (PA) was assessed using the popular Seven Day Physical Activity Recall (SDPAR) [13] questionnaire; it was chosen because of its high validity demonstrated among elderly individuals. The SDPAR questionnaire total score (daily energy expenditure within the last week) was calculated and used for the following comparisons. Physical disability was assessed by 2 scales: Activities of Daily Living (ADL) [14] and Instrumental Activities of Daily Living Scale (IADL) [15]. Functional status was assessed with the Timed Up and Go (TUG) [16] test, which looks at the abilities of transitioning from sitting to standing and walking short distances. Quality of life was assessed with the EuroQol 5D (EQ-5D) [17] questionnaire. It is a widely used and validated generic instrument with 5 dimensions: mobility, self-care, usual activities, pain/discomfort and anxiety/ depression. Each dimension has 3 levels: "no problems" (no limitations), "some problems" and "severe problems." In addition, each subject was asked to describe his or her overall actual health state using the EuroQol Visual Analogue Self-Esteem Scale (VASES) [18], where 0 denotes the worst imaginable health state and 100 indicates the best imaginable health state. All the research tools used in this study have been used in previous studies and validated in general and geriatric medicine over the years.

\section{Statistical analysis}

The results were verified for normality of distribution and equality of variance. The one-way analysis of variance (ANOVA), Mann-Whitney $U$ test or $\chi^{2}$ test were used for comparing the groups. EuroQol 5D dimension data was dichotomized (no problems vs. any problem) 
for statistical analyses. The multiple logistic regression was used for verifying whether the number of amalgam dental fillings was a predictor of RLS independently of age and gender and whether the presence of RLS was predictor of EuroQol 5D dimensions independently of age and gender. Odds ratios (OR) and confidence intervals (CI) with $95 \%$ confidence limits were calculated. The quantitative variables are presented as $\mathrm{M} \pm \mathrm{SD}$. The statistical analysis was performed using Statistica 12 CSS software. The limit of significance was set at $\mathrm{p}=0.05$ for all analyses.

\section{RESULTS}

The average age of respondents was $84 \pm 7.1$ years old. Forty-one subjects had RLS, and 63 did not. Out of the 41 subjects with RLS, 1 had very severe symptoms, 9 had severe, 23 moderate and 8 mild according to the IRLSSG Severity Rating Scale. Two women had also upper limbs RLS. Twenty subjects had coexisting current or previous problems such as anaemia, malaria, iron or vitamin B12 deficiency, which may have indicated secondary RLS. Within that group 1 woman's symptoms began in her thirties after pregnancy.

The Table 1 shows the characteristics of patients with and without RLS. Age and sex composition of both groups were similar. Subjects with RLS were characterized with lower physical activity (energy expenditure) level. The number of sleep hours per week, physical function (ADL, IADL, TUG) and cognitive functioning
(GDS and MMSE) were similar in both groups. Subjects with RLS had a significantly higher number of amalgam dental fillings as compared to the subjects without RLS symptoms (Table 1). For those subjects who at one time had amalgam fillings, but were later removed, the data was statistically insignificant in this study. Likewise, incidence and severity of RLS had no association to the presence of other metal dental restorative materials, history of depression or other diseases, alcohol intake and smoking status (not shown in the table).

Subjects who answered "yes" (indicating presence of RLS) to the 4 consecutive questions had a significantly higher number of amalgam dental fillings (2.3 vs. 1.0, 2.5 vs. $0.9,2.3$ vs. 1.2 and 2.5 vs. 1.1 , respectively) as compared to the subjects without RLS symptoms ( $\mathrm{p}$-values were $0.04,0.01,0.08$ and 0.03 , respectively). The group that had the largest number of amalgam fillings (7-13) had the greatest incidence (77.8\%) of RLS. In those with $1-6$ fillings the percentage was $42.1 \%$ whereas those with no fillings the percentage was $31.6 \%\left(2 \times 3 \chi^{2}, \mathrm{p}=\right.$ 0.028) (Figure 1).

The multiple logistic regression confirmed that the number of amalgam dental fillings was predictor of RLS independently of age and gender:

$$
\mathrm{OR}(\mathrm{CI})=1.20 \times(1.02-1.42) \times(\mathrm{p}=0.021)
$$

The Table 2 presents the results of the EQ-5D questionnaire. Subjects with RLS had more mobility and

Table 1. Clinical characteristics of older Polish immigrants aged 60-97 from various questionnaires conducted during 2012-2013 in Penrhos (North West Wales)

\begin{tabular}{|c|c|c|c|}
\hline Variable & $\begin{array}{l}\text { Without RLS } \\
\qquad(\mathrm{N}=63)\end{array}$ & $\begin{array}{l}\text { With RLS } \\
(\mathrm{N}=41)\end{array}$ & $\mathrm{p}$ \\
\hline Age [years] $(\mathrm{M} \pm \mathrm{SD})$ & $83.2 \pm 8.0$ & $84.1 \pm 7.2$ & 0.572 \\
\hline Amalgams $[\mathrm{n}](\mathrm{M} \pm \mathrm{SD})$ & $1.2 \pm 2.0$ & $2.4 \pm 3.5$ & 0.012 \\
\hline Sleep [h/week] $(\mathrm{M} \pm \mathrm{SD})$ & $49.5 \pm 10.6$ & $47.5 \pm 12.6$ & 0.387 \\
\hline depression in medical history [\%] & 15.9 & 26.8 & 0.174 \\
\hline energy expenditure [kcal/day] $(\mathrm{M} \pm \mathrm{SD})$ & $2963 \pm 892$ & $2610 \pm 493$ & 0.023 \\
\hline MMSE [pts] (M \pm SD) & $24.6 \pm 4.5$ & $23.9 \pm 5.4$ & 0.593 \\
\hline $\mathrm{IADL}[\mathrm{pts}](\mathrm{M} \pm \mathrm{SD})$ & $5.9 \pm 2.3$ & $6.3 \pm 1.8$ & 0.727 \\
\hline
\end{tabular}

RLS - restless legs syndrome, GDS - Geriatric Depression Scale [12], MMSE - Mini-Mental State Examination [11], IADL - Instrumental Activities of Daily Living [15], ADL - Activities of Daily Living [14], TUG - Timed Up and Go test [16].

Bolded - statistically significant. 


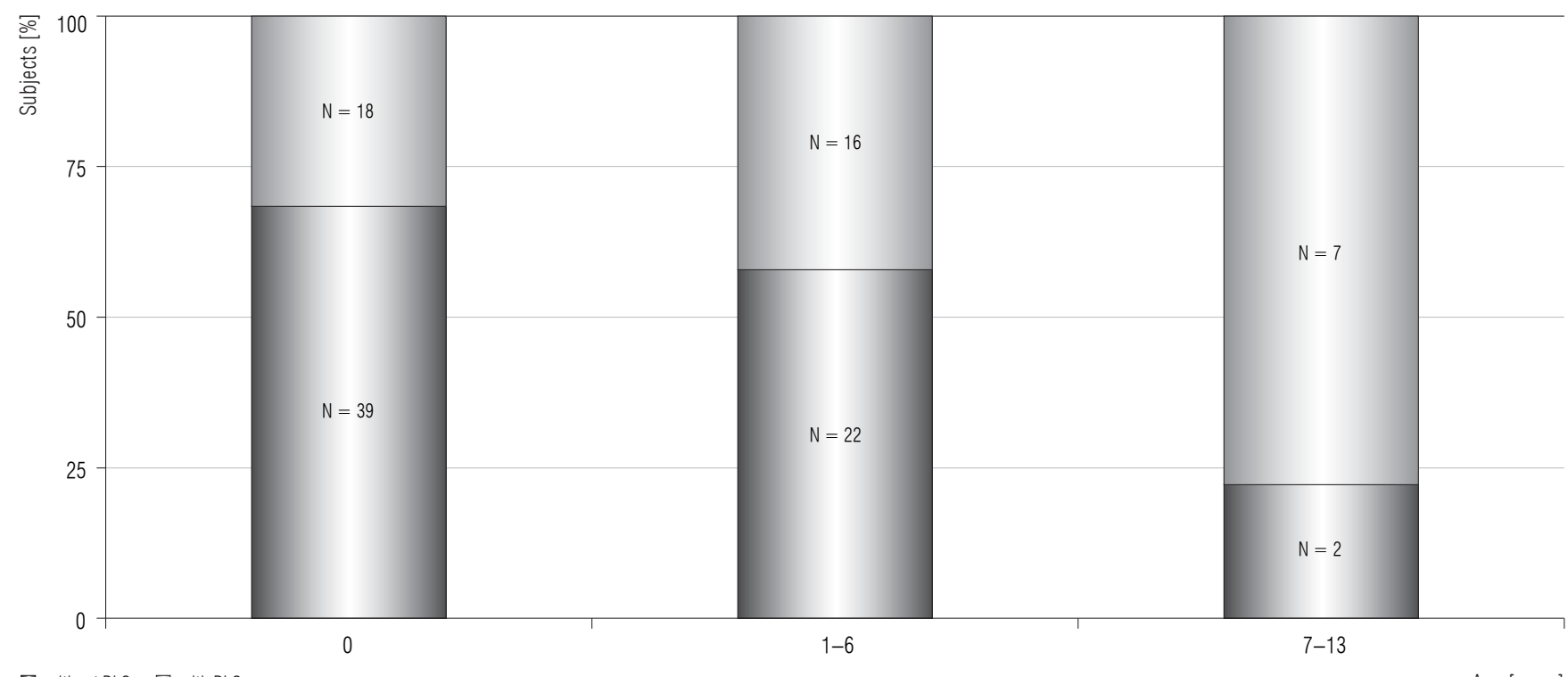

$\square$ without RLS $\square$ with RLS

Figure 1. Prevalence of restless legs syndrome depending on the number of amalgam dental fillings $(0,1-6,7-13)$ in the group of older subjects (60-97 years old) conducted in 2012-2013 in Penrhos (North West Wales)

Table 2. Quality of life for subjects with and without restless legs syndrome (RLS) examined with EuroQol 5D [17] during 2012-2013 in Penrhos (North West Wales)

\begin{tabular}{|c|c|c|c|}
\hline Variable & $\begin{array}{c}\text { Without RLS } \\
\qquad(\mathrm{N}=63)\end{array}$ & $\begin{array}{l}\text { With RLS } \\
(\mathrm{N}=41)\end{array}$ & $\mathrm{p}$ \\
\hline Mobility [n (\%)] & & & 0.023 \\
\hline no problems & $31(49.2)$ & $11(26.8)$ & \\
\hline moderate & $29(46)$ & $28(68.3)$ & \\
\hline severe & $3(4.8)$ & $2(4.9)$ & \\
\hline Self-care $[\mathrm{n}(\%)]$ & & & 0.464 \\
\hline no problems & $50(79.4)$ & $30(73.2)$ & \\
\hline moderate & $9(14.3)$ & $10(24.4)$ & \\
\hline severe & $4(6.3)$ & $1(2.4)$ & \\
\hline Usual activities [n (\%)] & & & 0.026 \\
\hline no problems & $43(68.3)$ & $19(46.3)$ & \\
\hline moderate & $15(23.8)$ & $19(46.3)$ & \\
\hline severe & $5(7.9)$ & $3(7.3)$ & \\
\hline Pain/discomfort [n (\%)] & & & 0.411 \\
\hline no problems & $15(23.8)$ & $7(17.1)$ & \\
\hline moderate & $42(66.7)$ & $33(80.5)$ & \\
\hline severe & $6(9.5)$ & $1(2.4)$ & \\
\hline Anxiety/depression [n (\%)] & & & 0.267 \\
\hline no problems & $30(47.6)$ & $15(36.6)$ & \\
\hline moderate & $32(50.8)$ & $23(56.1)$ & \\
\hline severe & $1(1.6)$ & $3(7.3)$ & \\
\hline Visual analogue scale $[\mathrm{pts}](\mathrm{M} \pm \mathrm{SD})$ & $62.1 \pm 16.6$ & $60.0 \pm 18.9$ & 0.559 \\
\hline
\end{tabular}


usual activities problems as compared to their healthy peers.

The multiple logistic regression confirmed that the presence of RLS was predictor of mobility problems independently of age and gender:

$$
\mathrm{OR}(\mathrm{CI})=2.62 \times(1.10-6.28) \times(\mathrm{p}=0.024)
$$

The multiple logistic regression confirmed that the presence of RLS was predictor of usual activities problems independently of age and gender:

$$
\mathrm{OR}(\mathrm{CI})=2.36 \times(1.01-5.54) \times(\mathrm{p}=0.045)
$$

\section{DISCUSSION}

To the best of our knowledge, this is the first study showing that amalgam fillings may be implicated in the appearance of RLS and contribute to lower QoL in older subjects. Restless legs syndrome in the elderly and general populations is associated with sleep impairment, depression, lower QoL and increased risk of mortality. People with RLS often describe the sensations in their limbs as pain. The elderly population usually have many painful conditions or sleep disturbance and it is difficult to differentiate between the causes. Therefore, several diagnostic tools have been proposed to detect RLS, of which the IRLSSG questionnaire for the diagnosis of RLS is the most widely used.

Toxic influences of $\mathrm{Hg}$ may be considered to be a potential contributor to RLS occurrence. Amalgam fillings have been important sources of $\mathrm{Hg}$ in the body for many years. Amalgam has been used for filling the body of the tooth and in the restoration of carious roots. This amalgam has been shown to infiltrate areas around the teeth [19].

Metal $\mathrm{Hg}$ plus $\mathrm{Hg}$ vapor inhaled from the oral cavity is then absorbed via the buccal membranes entering the bloodstream of a pulp vascular system and is deposited in the organs, e.g. kidney, brain and some is excreted in the urine [20]. Mercury is also released from amalgam by using chewing gums [21], nicotine gums [22] and to a lesser extent from bruxism [23]. A variety of authors indicate that amalgam corrosion and $\mathrm{Hg}$ release is increased by contact with different metal fillings. Thus, there is a progression of $\mathrm{Hg}$ release and uptake and this changes over time and circumstances.

Zander et al. [24] showed that exposure from $\mathrm{Hg}$ fillings was higher than that from food and other sources. Paradoxically, removal of amalgam filling may release the $\mathrm{Hg}$ thus adding to the body burden [25] (and indeed some mercury may be left behind in the root cavity and remains in the organs). To sum up, initially some $\mathrm{Hg}$ as a vapor occurs on the introduction of fillings and later continually emits vapor during chewing, bruxism, eating, brushing, drinking hot liquids [26], during subsequent deterioration of filling and even on removal. All of this leads to a lifetime of possible toxic accumulation of $\mathrm{Hg}$ and the implications of this are serious.

Not all people with amalgam fillings exhibit RLS symptoms. Conversely, some people with RLS do not appear to have had amalgam fillings. The latter being difficult to categorically prove, as these fillings may have been removed and the person does not remember. Even when the amalgam fillings have been removed the previously released $\mathrm{Hg}$ remains in the organs [9]. However, the concentration of mercury in people's bodies varies [27], which may explain the different intensity of paroxysmal sensations.

Other potential sources of $\mathrm{Hg}$ in the body should also be taken into consideration. Mercury not only enters the body from the environment such as through food chain, but also by occupational exposure and from industry, e.g., pollution of soil, water or air $[28,29]$. Since this contamination is widespread and not adequately regulated it is possible that the accumulation of $\mathrm{Hg}$ in the body comes from a variety of sources. Although the individual sources of $\mathrm{Hg}$ have a maximum dose, it is the accumulation from various sources that is the concern. Dórea et al. [30] noted that toxicity profiles from ethylmercury (etHg) and methylmercury $(\mathrm{meHg})$ are different with different exposure and toxicity but exposure to both may enhance neurotoxic effects. Since this exposure starts in childhood and is continuous throughout life the implications are potentially serious and significant. Early exposure may begin in the womb because mothers may have injections preserved with Thimerosal [31] and may have amalgam fillings. Maternal and fetal hair mercury levels were significantly higher in women with amalgam restorations, no matter if dental amalgam had been placed before or during pregnancy [32]. Thimerosal containing $49.6 \%$ by weight of ethyl $\mathrm{Hg}$, may be hazardous to health and yet it is the most widely used form of organic $\mathrm{Hg}$, occurring in various pharmaceuticals, cosmetics, topical beauty creams and teething powders [33]. Mothers living in Minamata ate food contaminated with methylmercury and this passed through the placenta. Following the Minamata disaster babies were born with serious and extensive brain lesions. This congenital condition is called Minamata 
disease (M. d.). Gotelli stated that the "dose make the poison" while describing an incident when a disinfectant containing $\mathrm{Hg}$ salt was used by a commercial diaper washing service in Buenos Aires in 1981. Due to the absorption of phenyl mercury through their skin, 1600 babies were poisoned. This affected their urinary excretion, some become light phobic and had neurological difficulties such as flaccid muscles [34]. Mercury is known to enter breast milk [35] following a mother's exposure to $\mathrm{Hg}$. In addition, $\mathrm{Hg}$ may enter the child's body from childhood vaccinations because thimerosal is used as a preservative in vaccinations. Childhood exposure to $\mathrm{Hg}$ has been implicated in the risk of autism, ADHD and neurological problems in the offspring [36].

Several shortcomings of this study should be acknowledged. The relationship of RLS to the presence of current amalgam fillings and some aspects of QoL were observed. For those subjects who at one time had amalgam fillings, but were later removed, and at the same time they showed RLS symptoms, the data was statistically insignificant in this study. Older subjects may not remember the number of fillings and other dental interventions. On the other hand, to minimize those potential biases only subjects without cognitive impairment were included to the study. Each person's reaction to each exposure is variable due to personal sensitivity and may be governed by genetic variations and/or predisposition [37]. It is not known why some people exhibit symptoms, more severe symptoms or none. It may be indeed "dose" related or the individual's response to that dose. Another factor is that some people are hypersensitive to $\mathrm{Hg}$ with an autoimmune system that is compromised, and they may exhibit allergic symptoms [38]. Therefore, current findings should be corroborated in future studies assessing other aspects of $\mathrm{Hg}$ toxicity from the dental amalgam. For example, the relatively new data about an increased mercury release after exposure to electromagnetic fields (as those generated by mobile phones or MRI) $[36,39]$. Identifying them is a major challenge and worthy of investigation. Future studies should relate the occurrence of RLS to the mercury concentrations in urine.

In the literature, there are descriptions of the condition that would be identified as RLS now. Charles Dickens' largely autobiographical story David Copperfield with its' observation of self and/or others said of the waiter: "At last I rose to bed, much to the relief of the sleepy waiter, who had got the fidgets in his legs, and was twisting them, and putting them through all kinds of contortions" [40].
Charles Dickens himself as a child, worked in a shoe blacking manufacturing establishment. The blacking was made from soot which contains mercury Iodide $\left(\mathrm{HgI}_{2}\right)$. The exposure is inevitable, but it is necessary to minimize it and research into this would be advantageous for present and future generations.

\section{CONCLUSIONS}

In conclusion, older subjects with the presence of symptoms of RLS had a significantly higher number of amalgam dental fillings as compared to the subjects without RLS symptoms. Therefore, while examining the correlates of the appearance of restless legs syndrome, the use of amalgam in the dentition should be taken into account.

\section{REFERENCES}

1. Willis T. The London practice of physick, or, the whole practical part of physick. London: Thomas Basset and William Crooke; 1685.

2. Cuellar NG, Strumpf NE, Ratcliffe SJ. Symptoms of restless legs syndrome in older adults: Outcomes on sleep quality, sleepiness, fatigue, depression, and quality of life. J Am Geriatr Soc. 2007;55(9):1387-92, https://doi.org/10.1111/j.15325415.2007.01294.x.

3. Nagandla K, De S. Restless legs syndrome: Pathophysiology and modern management. Postgrad Med J. 2013;89 (1053):402-10, https://doi.org/10.1136/postgradmedj-2012131634.

4. Li Y, Wang W, Winkelman JW, Malhotra A, Ma J, Gao X. Prospective study of restless legs syndrome and mortality among men. Neurology. 2013;81(1):52-9, https://doi. org/10.1212/WNL.0b013e318297eee0.

5. Allen RP, Picchietti DL, Garcia-Borreguero D, Ondo WG, Walters AS, Winkelman JW, et al. Restless legs syndrome/ Willis-Ekbom disease diagnostic criteria: Updated International Restless Legs Syndrome Study Group (IRLSSG) consensus criteria - History, rationale, description, and significance. Sleep Med. 2014;15(8):860-73, https://doi.org/ 10.1016/j.sleep.2014.03.025.

6. Kozlowski H, Kolkowska P, Watly J, Krzywoszynska K, Potocki S. General aspects of metal toxicity. Curr Med Chem. 2014;21(33):3721-40, https://doi.org/10.2174/09298 67321666140716093838 .

7. Xu F, Farkas S, Kortbeek S, Zhang FX, Chen L, Zamponi GW, et al. Mercury-induced toxicity of rat cortical neurons is mediated through N-Methyl-D-Aspartate receptors. Mol Brain. 2012;5:30, https://doi.org/10.1186/1756-6606-5-30. 
8. Voitzuk A, Greco V, Caputo D, Alvarez E. [Toxic nephrophaty secondary to occupational exposure to metallic mercury]. Med (B Aires). 2014;74(5):397-9. Spanish.

9. Björkman L, Lundekvam BF, Laegreid T, Bertelsen BI, Morild I, Lilleng P, et al. Mercury in human brain, blood, muscle and toenails in relation to exposure: An autopsy study. Environ Health. 2007;6:30, https://doi.org/10.1186/1476069X-6-30

10. The International Restless Legs Syndrome Study Group. Validation of the International Restless Legs Syndrome Study Group Rating Scale for restless legs syndrome. Sleep Med. 2003;4(2):121-32, https://doi.org/10.1016/S1389-94 57(02)00258-7.

11. Folstein MF, Folstein SE, McHugh PR. "Mini-Mental State": A practical method for grading the cognitive state of patients for the clinician. J Psychiatric Research. 1975;112: 189-98, https://doi.org/10.1016/0022-3956(75)90026-6.

12. Yesavage JA, Brink T, Lom O. Development and validation of a geriatric depression screening scale: A preliminary report. J Psychiatr Res. 1983;17:37-49, https://doi.org/10.10 16/0022-3956(82)90033-4.

13. Blair SN, Haskell WL, Ho P, Paffenbarger RS Jr, Vranizan KM, Farquhar JW, et al. Assessment of habitual physical activity by a seven-day recall in a community survey and controlled experiments. Am J Epidemiol. 1985;122:794804, https://doi.org/10.1093/oxfordjournals.aje.a114163.

14. Katz S, Ford AB, Moskowitz RW, Jackson BA, Jaffe MW. Studies of illness in the aged: The index of ADL, a standardized measure of biogical and psychosocial function. JAMA. 1963;185:914-9, https://doi.org/10.1001/jama.19 63.03060120024016 .

15. Lawton M, Brody E. Instrumental Activities of Daily Living (IADL) Scale: Orginal observer-rated version. Psychopharmacol Bulletin. 1988;24:785-92.

16. Podsiadlo D, Richardson S. The timed "Up \& Go": A test of basic functional mobility for frail elderly persons. J Am Geriatr Soc. 1991;39(2):142-8, https://doi.org/10.1111/j.15 32-5415.1991.tb01616.x.

17. EuroQol Group. EuroQol - A new facility for the measurement of health-related quality of life. Health Policy. 1990;16(3):199-208, https://doi.org/10.1016/0168-8510(90) 90421-9.

18. Brumfitt SM, Sheeran P. The development and validation of the Visual Analogue Self-Esteem Scale (VASES). Br J Clin Psychol. 1999;38(Pt 4):387-400, https://doi.org/10. 1348/014466599162980.

19. Harris HH, Vogt S, Eastgate H, Legnini DG, Hornberger B, Cai Z, et al. Migration of mercury from dental amalgam through human teeth. J Synchrotron Radiat. 2008;15(Pt 2): 123-8, https://doi.org/10.1107/S0909049507061468.
20. Bjørklund G, Dadar M, Mutter J, Aaseth J. The toxicology of mercury: Current research and emerging trends. Environ Res. 2017;159:545-4, https://doi.org/10.1016/j.envres.2017.08.051.

21. Gebel T, Dunkelberg H. [Influence of chewing gum consumption and dental contact of amalgam fillings to different metal restorations on urine mercury content]. Zentralbl Hyg Umweltmed. 1996;199(1):69-75. German.

22. Sällsten G, Thorén J, Barregård L, Schütz A, Skarping G. Long-term use of nicotine chewing gum and mercury exposure from dental amalgam fillings. J Dent Res. 1996;75(1):594-8, https://doi.org/10.1177/002203459607 50011301.

23. Isacsson G, Barregård L, Seldén A, Bodin L. Impact of nocturnal bruxism on mercury uptake from dental amalgams. Eur J Oral Sci. 1997;105(3):251-7, https://doi.org/ 10.1111/j.1600-0722.1997.tb00208.x.

24. Zander D, Ewers U, Freier I, Westerweller S, Jermann E, Brockhaus A. [Exposure to mercury in the population. II. Mercury release from amalgam fillings]. Zentralbl Hyg Umweltmed. 1990;190(4):325-34. German.

25. Sandborgh-Englund G, Elinder CG, Langworth S, Schütz A, Ekstrand J. Mercury in biological fluids after amalgam removal. J Dent Res. 1998;77(4):615-24, https://doi.org/ 10.1177/00220345980770041501.

26. Fredin B. Mercury release from dental amalgam fillings. Int J Risk Saf Med. 1994;4(3):197-208, https://doi.org/ 10.3233/JRS-1994-4303.

27. Barregård L, Sällsten G, Järvholm B. People with high mercury uptake from their own dental amalgam fillings. Occup Environ Med. 1995;52(2):124-8, https://doi.org/10.11 36/oem.52.2.124.

28. Affelska-Jercha A. [The toxic effect of mercury in occupational exposure]. Med Pr. 1999;50(4):305-14. Polish.

29. Rice KM, Walker EM Jr, Wu M, Gillette C, Blough ER. Environmental mercury and its toxic effects. J Prev Med Public Health. 2014;47(2):74-83, https://doi.org/10.3961/ jpmph.2014.47.2.74.

30. Dórea JG, Farina M, Rocha JB. Toxicity of ethylmercury (and thimerosal): A comparison with methylmercury. J Appl Toxicol. 2013;33(8):700-11, https://doi.org/10.1002/ jat.2855.

31. Tamma PD, Ault KA, del Rio C, Steinhoff MC, Halsey NA, Omer SB. Safety of influenza vaccination during pregnancy. Am J Obstet Gynecol. 2009;201(6):547-52, https://doi. org/10.1016/j.ajog.2009.09.034.

32. Lindow SW, Knight R, Batty J, Haswell SJ. Maternal and neonatal hair mercury concentrations: The effect of dental amalgam. BJOG. 2003;110(3):287-91, https://doi.org/ 10.1046/j.1471-0528.2003.02257.x. 
33. Dórea JG. Low-dose Thimerosal (ethyl-mercury) is still used in infants' vaccines: Should we be concerned with this form of exposure? J Trace Elem Med Biol. 2018;49:134-9, https://doi.org/10.1016/j.jtemb.2018.05.010.

34. Gotelli CA, Astolfi E, Cox C, Cernichiari E, Clarkson TW. Early biochemical effects of an organic mercury fungicide on infants: "Dose makes the poison." Science. 1985; 227(4687):638-40, https://doi.org/10.1126/science.28 57500.

35. Al-Saleh I, Abduljabbar M, Al-Rouqi R, Elkhatib R, Alshabbaheen A, Shinwari N. Mercury (Hg) exposure in breastfed infants and their mothers and the evidence of oxidative stress. Biol Trace Elem Res. 2013;153(1-3):145-54, https://doi.org/10.1007/s12011-013-9687-7.

36. Mortazavi G, Haghani M, Rastegarian N, Zarei S, Mortazavi SM. Increased release of mercury from dental amalgam fillings due to maternal exposure to electromagnetic fields as a possible mechanism for the high rates of autism in the offspring: Introducing a hypothesis. J Biomed Phys Eng. 2016;6(1):41-6.

37. Woods JS, Heyer NJ, Russo JE, Martin MD, Farin FM. Genetic polymorphisms affecting susceptibility to mercury neurotoxicity in children: Summary findings from the Casa Pia Children's Amalgam Clinical Trial. Neurotoxicology. 2014;44:288-302, https://doi.org/10.1016/j.neuro.20 14.07.010.

38. Kieć-Świerczyńska M. [Mercury as an allergic factor]. Med Pr. 2009;60(4):303-14. Polish.

39. Mortazavi G, Mortazavi SM. Increased mercury release from dental amalgam restorations after exposure to electromagnetic fields as a potential hazard for hypersensitive people and pregnant women. Rev Environ Health. 2015;30(4):287-92, https://doi.org/10.1515/reveh-20 15-0017.

40. Dickens C. David Copperfield. London: Bradbury \& Evans; 1850. Chapter 19. p. 203.

This work is available in Open Access model and licensed under a Creative Commons Attribution-NonCommercial 3.0 Poland License - http://creativecommons.org/licenses/by-nc/3.0/pl/deed.en. 